\title{
Glicemia, proteinograma e perfil de alguns componentes bioquímicos séricos de cabritos da raça Bôer
}

\author{
Glycemic, protein profile and serum biochemical profile in Bôer goat kids
}

\author{
Rodrigo YANAKA ${ }^{1}$; Diogo Gaubeur de CAMARGO ${ }^{2}$; Wildemberto Arena dos SANTOS ${ }^{2}$; Bruno da \\ Silva CAVASSANO ${ }^{2}$; Fernanda BOVINO ${ }^{2}$; Luiz Cláudio Nogueira MENDES $^{2}$; Juliana Regina PEIRÓ ${ }^{2}$; \\ Francisco Leydson Formiga FEITOSA ${ }^{2}$
}

1Unidade Acadêmica de Garanhuns da Universidade Federal Rural de Pernambuco, Garanhuns-PE

2Curso de Medicina Veterináriada Faculdade de Odontologia da Universidade Estadual Paulista "Júlio de Mesquita Filho", Araçatuba-SP

\begin{abstract}
Resumo
Os cabritos recém-nascidos sofrem diversas adaptações à vida extrauterina que afetam diferentes funções orgânicas, pois precisam produzir calor, iniciar a atividade muscular e buscar alimento. Todos estes eventos levam a modificações em diversos constituintes sanguíneos, como proteínas e parâmetros bioquímicos séricos. Outros estudos demonstraram estas variações, mas sem se estender além do período neonatal até a fase de animais jovens. Objetivou-se testar a hipótese de que ocorre variação doproteinograma, dos componentes bioquímicos e da glicemia de cabritos desde o nascimento até 75 dias de vida em função da adaptação à vida extrauterina. Para atingir estes objetivos, foram colhidas amostras de sangue de 25 cabritos nascidos de partos normais, independentemente do sexo. As variáveis séricas proteína total (PT), albumina, $\alpha$-globulina, $\beta$-globulina, $\gamma$-globulina, onde se incluem a imunoglobulina $\mathrm{G}(\mathrm{IgG})$, aspartatoaminotransferase (AST), fosfatase alcalina (FA), gamaglutamiltransferase (GGT), creatinina, ureia, e glicemia foram determinadas nos momentos zero (logo após o nascimento), dois, sete, 15, 30 e 75 dias pós-parto. Observaram-se diferenças significativas em todas as variáveis entre os momentos, mas somente a concentração de creatinina foi maior que aquelas dos demais momentos, nos tempos zero e de dois dias pós-nascimento, devido, provavelmente, à imaturidade da função renal em animais neonatos. Os constituintes sanguíneos dos cabritos tiveram variações no período avaliado, relacionados a causas fisiológicas e nutricionais.
\end{abstract}

Palavras-chave: Caprino. Neonatos. Função renal.Proteinograma.Funçãohepática.

\begin{abstract}
The newborn goat kids suffer several adjustments to life outside the uterus that affect different body functions that they need to produce heat, muscle activity and start searching for food. All these events lead to changes in several blood constituents such as proteins and serum biochemical parameters. Other studies have shown these variations, but not extend beyond the neonatal period to phase in young animals. The aim was to test the hypothesis that there is variation of the protein profile, and biochemical components of blood glucose in goat kids from birth to 75 days of life in terms of adaptation to extra uterine life. To achieve these objectives have been collected blood samples from 25 goats born by normal delivery, regardless of their sex. The variables serum total protein (TP), albumin, a-globulin, $\beta$-globulin, $\gamma$-globulin, which includes the immunoglobulin G (IgG), aspartate (AST), alkaline phosphatase (ALP), gamma-glutamyltransferase (GGT), creatinine and urea, and glucose were determined at times zero (immediately after birth), two, seven, 15, 30 and 75 days old. We observed significant differences in all variables between times, but only the creatinine concentration was higher than those of other moments in time zero and two days old, probably due to immaturity of renal function in newborn animals. The blood constituents of the kids had variations in the study period, related to physiological and nutritional causes.
\end{abstract}

Keywords: Caprine. Newborn. Renal function. Protein profile. Liverfunction.

Correspondência para:

Leydson Formiga Feitosa

Universidade Estadual Paulista "Júlio de Mesquita Filho"

Faculdade de Medicina Veterinária, UNESP Campus de Araçatuba,

Araçatuba-SP

Rua Clóvis Pestana, n. 793, Jardim Dona Amélia, Araçatuba-SP, Brasil

CEP: $16050-680$ e-mail: leydsonf@fmva.unesp.br

Recebido: 11/03/2011

Aprovado: 29/02/2012

Auxílio à pesquisa (processo n. 07/55829-9) e bolsa de mestrado (processo

n. 06/58492-2) concedida pela Fundação de Amparo à Pesquisa do Estado

de São Paulo (FAPESP) 


\section{Introdução}

Os recém-nascidos sofrem alterações orgânicas que podem influenciar diversos constituintes sanguíneos, devido à maturação funcional dos órgãos e sistemas, além da adaptação nutricional decorrente da ruptura do cordão umbilical no parto e finalização do transporte de nutrientes materno-fetal. Portanto, a necessidade energética para suportar a termorregulação, respiração e atividade muscular, encontra-se aumen$\operatorname{tada}^{1}$. A glicose sanguínea, um dos substratos energéticos primários disponíveis ao ruminante neonato ${ }^{2}$, é baixa no recém-nascido até a primeira ingestão de colostro $^{3}$. O colostro e/ou leite são as únicas fontes naturais de energia dietética disponíveis para o animal recém-nascido ${ }^{4}$;a concentração plasmática de glicose em ruminantes neonatos depende diretamente da quantidade ingerida desses alimentos e da concentração de lactose presente na secreção láctea ${ }^{5}$.

Além da função nutricional, o colostro tem grande importância no período neonatal em relação à transferência de imunidade passiva, pois $45,1 \%$ do total de proteínas presentes no colostro caprino são representados pela fração $\gamma$-globulina ${ }^{6}$, que contém as diferentes classes de imunoglobulinas ${ }^{7}$, com destaque para a imunoglobulina G (IgG), cuja concentração está associada à maior taxa de sobrevivência dos animais ${ }^{8,9}$. Após a ingestão de colostro, observou-se aumento da concentração de gamaglobulinas e IgG, e, consequentemente, da proteína total $(\mathrm{PT})$, no soro de cabritos ${ }^{10,11,12,13}$ porém, com pouca variação nas frações proteicas de albumina, $\alpha$-globulina e $\beta$-globulina até 30 horas pós-parto ${ }^{13}$.

A quantificação da atividade sérica de diversas enzimas, como a aspartatoaminotransferase (AST), fosfatase alcalina (FA) e gamaglutamiltransferase (GGT), e da concentração sérica de creatinina e ureia, pode fornecer diversas informações acerca do estado geral do paciente, além de contribuir para o diagnóstico de diversas enfermidades. A realização de análises clínicas enzimológicas, além da sua função primária como método auxiliar diagnóstico, pode ser utilizada, também, como medida indireta da transferência de imunidade passiva, como previamente descrito em caprinos $^{12,14}$, devido a sua presença no colostro ${ }^{6}$.

Há escassez de informações na literatura quanto às possíveis variações do proteinograma, das concentrações de diversos componentes bioquímicos e da glicemia em cabritos, pois a maioria dos trabalhos não contempla todo o período neonatal, que se estende até os primeiros 28 dias de vida ${ }^{13}$, assim como a fase de animais jovens, com avaliações mais concentradas apenas na primeira semana de vida, e direcionadas à avaliação da transferência de imunidade passiva. Porém, outras enfermidades podem acometer os caprinos no período compreendido entre o nascimento e 75 dias de vida, necessitando de outros exames laboratoriais complementares, evidenciando-se, assim, a importância de se conhecer não somente os valores referenciais, mas as possíveis variações, fisiológicas ou não, destes parâmetros, e as suas respectivas causas, no período neonatal e de transição para a vida adulta.

Isso posto, objetivou-se testar a hipótese de que há variação na glicemia, no proteinograma e no perfil sérico de alguns componentes bioquímicos de cabritos, desde o nascimento até os 75 dias de vida.

\section{Material e Método}

A glicemia e os perfis bioquímico e proteico sanguíneos foram determinados em 25 cabritos (11 machos e 14 fêmeas) da raça Bôer, oriundos de partos eutócicos, nos seguintes momentos: dia zero (logo após o nascimento, antes de mamar o colostro), bem como aos dois, sete, 15, 30 e 75 dias de vida. Foram incluídos apenas animais considerados hígidos, ao exame físico, nos diferentes períodos, por meio da avaliação da coloração de mucosas, linfonodos, bem como aferição dos parâmetros vitais (frequências cardíaca e respiratória e temperatura retal) segundo Feitosa ${ }^{15}$. 
Os cabritos foram mantidos com as mães nas primeiras 48 horas pós-parto e, posteriormente, submetidos a manejo de mamada controlada, nos períodos da manhã e da tarde, permanecendo, durante a noite, em baias cobertas, enquanto as cabras ficavam em piquete adjacente.

As amostras de sangue foram coletadas por venopunção jugular, em tubos sem anticoagulante, mantidos em temperatura ambiente e ao abrigo da luz, até a coagulação e retração do coágulo. Em seguida, foram centrifugadas a 3.000 r.p.m., durante cinco minutos, para separação do soro, que foi transferido para frascos de plástico apropriados, divididos em duas alíquotas congeladas imediatamente a $-20^{\circ} \mathrm{C}$, até o momento do seu processamento. Adicionalmente, colheu-se amostra de sangue total $(0,5 \mathrm{~mL})$ em seringa plástica acoplada à agulha hipodérmica, sem anticoagulante, para determinação imediata da glicemia, utilizando-se aparelho digital portátil (OneTouch Ultra 2, Johnson \& Johnson Medical S. A., São José dos Campos, São Paulo, Brasil) e respectivas tiras reagentes, de acordo com as recomendações do fabricante.

Determinaram-se as concentrações sanguíneas da proteína total (PT), frações eletroforéticas (albumina, a-globulina, $\beta$-globulina e $\gamma$-globulina), imunoglobulina $\mathrm{G}$ (IgG), creatinina, ureia e as atividades séricas de aspartatoaminotransferase (AST), fosfatase alcalina (FA) e gamaglutamiltransferase (GGT).

A proteína total sérica foi determinada pelo método de refratometria, utilizando-se refratômetro clínico (Clinicalrefractometer Master-SUR/NM, Atago, Honcho, Itabashi-ku, Tóquio, Japão).

Efetuou-se a migração eletroforética para separação das frações proteicas séricas segundo as técnicas descritas por Friedman ${ }^{16}$ e Kremers, Briere e Batasakis ${ }^{17}$, citados por Strufaldi ${ }^{18}$, utilizando fitas de acetato de celulose de 2,5x14,0 cm (Cellogel', M.A.L.T.A. Chemetron, Via Console Flamino 5, Milano, Itália).

A leitura do fracionamento eletroforético foi realizada em densitômetro para eletroforese (Quickscan
2000, Helena Laboratories, Beaumont, Texas, EUA), com marcação automática das diferentes frações proteicas por programa computacional (Quickscan 2000 Win, Helena Laboratories, Beaumont, Texas, EUA).

Realizaram-se as determinações da IgG segundo a técnica de Fahey e McKelvey ${ }^{19}$ e Mancini, Carbonara e Heremans ${ }^{20}$, utilizando-se placas de ágar incorporadas com anticorpos específicos para a classe de IgG de caprinos (CapIgG Test, IDBiotech, Avenue Marie Curie, Issoire, França). A quantidade de imunoglobulina em questão foi estimada, observando-se a concentração de imunoglobulinas correspondente a cada amostra, pela simulação computacional da equação de regressão e gráfico com os valores obtidos para os respectivos padrões de IgG, fornecidos pelo fabricante.

Realizaram-se as análises bioquímicas em analisador bioquímico semi-automático (QuickLab 2, Drake Eletrônica Comércio Ltda., São Paulo, Brasil), após verificação do controle de qualidade com controles comerciais $1 \mathrm{H}$ e $2 \mathrm{H}$ (Qualitrol $1 \mathrm{H}$ e $2 \mathrm{H}$, Labtest, Lagoa Santa, Minas Gerais, Brasil), além do controle padrão interno do laboratório. As concentrações séricas da GGT, determinadas pelo método cinético colorimétrico; da FA, pelo método cinético; e da AST, pelo método cinético UV, enzimático. Foram determinadas usando-se "kits" comerciais (Katal Biotecnológica, Belo Horizonte, Minas Gerais, Brasil).

As concentrações de ureia (Ureia, Katal Biotecnológica, cod. 17B, Belo Horizonte, Minas Gerais, Brasil) e creatinina (Creatinina-Labtest, Labtest, Lagoa Santa, Minas Gerais, Brasil) foram determinadas pelo método enzimático colorimétrico, utilizando-se "kits"comerciais.

De acordo com os resultados dos testes de normalidade (Kolmogorov-Smirnov) e homocedasticidade (Bartlett), os dados foram submetidos à análise de variância paramétrica (ANOVA) ou não paramétrica (Friedman) com medidas repetidas, seguidos dos testes de Tukey ou Dunn, respectivamente, para veri- 
ficação das diferenças entre os momentos. As análises foram consideradas significativas quando $\mathrm{p}<0,05$.

\section{Resultados e Discussão}

O proteinograma sérico de cabritos apresentou variações significativas desde o nascimento até os 75 dias de vida (Tabela 1).

A concentração sérica de proteína total dos cabritos, antes da ingestão de colostro, mostrou-se abaixo do intervalo de referência para a espécie, de 6,4 a 7,0 $\mathrm{g} / \mathrm{dL}^{21}$ e de $7,2 \pm 1,1 \mathrm{~g} / \mathrm{dL}^{22}$, com valor máximo aos dois dias de vida, seguida de posterior declínio até os 75 dias de vida (Tabela 1).O aumento da PT, aos dois dias de vida (Tabela 1), deveu-se à absorção de globulinas presentes no colostro ${ }^{23,24}$, em especial da fração gamaglobulina, onde se encontra distribuída parte da imunoglobulina $G^{23,25,26}$. Este comportamento decorreu dos resultados obtidos, com aumentos significativos das frações alfa, beta e gamaglobulinas, entre o nascimento e os dois dias de vida (Tabela 1). A estabilidade da concentração da albumina sugere que esta fração não colaborou para o incremento das concentrações de PT. A influência da ingestão de colostro sobre o proteinograma de caprinos também foi observada por outros autores que relataram que este se caracterizou por aumento significativo da proteína total, frações globulinicas e $\operatorname{IgG}^{8,10,11,12,13,27,28,29}$.

O declínio significativo da PT, entre dois e 30 dias de idade (Tabela 1), deveu-se, provavelmente, ao catabolismo das imunoglobulinas adquiridas do colostro durante a fase neonatal, período em que o sistema imune ainda não possui suficiente competência para produzir e manter seus níveis elevados. Este fato foi comprovado pela concomitante diminuição dos teores de gamaglobulinas e, consequentemente, de IgG, no mesmo período (Tabela 1). Aos 75 dias de idade, as concentrações de PT, gamaglobulina e IgG não foram significativamente diferentes daquelas mensuradas aos 30 dias, sugerindo que, a partir deste período, já começa a haver estabilização destes parâmetros, devido à produção ativa das diferentes classes de imunoglobulinas.

Tabela 1 - Médias e desvios-padrão das concentrações séricas de proteína total, albumina, $\alpha$-globulina, $\beta$-globulina, $\gamma$-globulina e imunoglobulina $G(\operatorname{IgG})$ de cabritos da raça Bôer $(n=25)$ desde o nascimento até 75 dias de vida - Araçatuba - 2010

\begin{tabular}{|c|c|c|c|c|c|c|}
\hline \multirow{2}{*}{ Variável } & \multicolumn{6}{|c|}{ Momento (dias) } \\
\hline & $\mathbf{0}$ & 2 & 7 & 15 & 30 & 75 \\
\hline Proteína total (g/dL) & $\begin{array}{l}3,76^{\mathrm{e}} \\
(0,40)\end{array}$ & $\begin{array}{c}6,82^{\mathrm{a}} \\
(0,91)\end{array}$ & $\begin{array}{l}6,56^{\mathrm{ab}} \\
(0,65)\end{array}$ & $\begin{array}{l}6,05^{\mathrm{abc}} \\
(0,42)\end{array}$ & $\begin{array}{l}5,63^{\mathrm{cd}} \\
(0,34)\end{array}$ & $\begin{array}{l}5,18^{\mathrm{de}} \\
(0,51)\end{array}$ \\
\hline Albumina (g/dL) & $\begin{array}{l}2,64^{\mathrm{cd}} \\
(0,33)\end{array}$ & $\begin{array}{l}2,48^{\mathrm{d}} \\
(0,25)\end{array}$ & $\begin{array}{l}2,68^{\mathrm{cd}} \\
(0,28)\end{array}$ & $\begin{array}{l}3,16^{\mathrm{ab}} \\
(0,20)\end{array}$ & $\begin{array}{c}3,34^{\mathrm{a}} \\
(0,28)\end{array}$ & $\begin{array}{l}2,89^{\mathrm{bc}} \\
(0,37)\end{array}$ \\
\hline a-globulina (g/dL) & $\begin{array}{c}0,42^{\mathrm{b}} \\
(0,11)\end{array}$ & $\begin{array}{c}0,53^{\mathrm{a}} \\
(0,13)\end{array}$ & $\begin{array}{c}0,55^{\mathrm{a}} \\
(0,10)\end{array}$ & $\begin{array}{l}0,49^{\mathrm{ab}} \\
(0,08)\end{array}$ & $\begin{array}{l}0,51^{\mathrm{ab}} \\
(0,10)\end{array}$ & $\begin{array}{l}0,48^{\mathrm{ab}} \\
(0,07)\end{array}$ \\
\hline$\beta$-globulina (g/dL) & $\begin{array}{c}0,59^{\mathrm{e}} \\
(0,09)\end{array}$ & $\begin{array}{l}0,82^{\mathrm{ab}} \\
(0,10)\end{array}$ & $\begin{array}{c}0,85^{\mathrm{a}} \\
(0,12)\end{array}$ & $\begin{array}{l}0,76^{\text {bc }} \\
(0,07)\end{array}$ & $\begin{array}{l}0,72^{\mathrm{cd}} \\
(0,10)\end{array}$ & $\begin{array}{c}0,87^{\mathrm{a}} \\
(0,09)\end{array}$ \\
\hline$\gamma$-globulina $(\mathrm{g} / \mathrm{dL})$ & $\begin{array}{c}0,09^{\mathrm{e}} \\
(0,03)\end{array}$ & $\begin{array}{c}3,05^{\mathrm{a}} \\
(0,85)\end{array}$ & $\begin{array}{l}2,27^{\mathrm{ab}} \\
(0,40)\end{array}$ & $\begin{array}{l}1,64^{\mathrm{bc}} \\
(0,38)\end{array}$ & $\begin{array}{c}1,07 c \\
(0,20)\end{array}$ & $\begin{array}{l}1,05^{\mathrm{cd}} \\
(0,24)\end{array}$ \\
\hline $\begin{array}{c}\text { IgG } \\
(\mathrm{mg} / \mathrm{dL})\end{array}$ & $\begin{array}{c}3,61^{\mathrm{f}} \\
(1,34)\end{array}$ & $\begin{array}{c}3166,24^{\mathrm{a}} \\
(1202,14)\end{array}$ & $\begin{array}{c}2367,19^{\mathrm{ab}} \\
(968,63)\end{array}$ & $\begin{array}{c}1650,92^{\mathrm{bcd}} \\
(611,02)\end{array}$ & $\begin{array}{c}1318,38^{\text {cde }} \\
(410,20)\end{array}$ & $\begin{array}{c}1711,68^{b c} \\
(655,16)\end{array}$ \\
\hline
\end{tabular}

Médias seguidas de letras distintas, na linha, diferem entre si $(\mathrm{p}<0,05)$ 
Os valores médios de albumina dos cabritos permaneceram estáveis nos primeiros sete dias de vida, sendo que,aos 15 e 30 dias, houve importante aumento desta fração (Tabela 1), influenciado, possivelmente, pela alteração nutricional, pois, nesta faixa etária, os animais começaram naturalmente a buscar alimentação sólida, o que associada à ingestão de leite, contribuiu para aumentar o nível proteico desta. Aos 75 dias houve diminuição significativa em relação aos teores de albumina verificados aos 30 dias de idade (Tabela 1); este declínio coincidiu com o período de diminuição da produção de leite pelas cabras, o que, provavelmente, foi fator de influência para ocorrência deste decréscimo. Porém, as taxas de albumina permaneceram próximas às observadas por Birgel ${ }^{30}$, de 2,49 $\pm 0,096 \mathrm{~g} / \mathrm{dL}$, em caprinos com até seis meses de idade.

Osoutros componentes bioquímicos séricos estabelecidos nos cabritos com as determinações realizadas desde o nascimento até os 75 dias de vida estãoapresentados na tabela 2. Todas as variáveis mensuradas apresentaram diferenças significativas entre os momentos.
As atividades séricas de AST estavam próximas ou abaixo dos valores relatados como de referência por $\mathrm{Kerr}^{31}$, de até $100 \mathrm{UI} / \mathrm{L}$, para a maioria das espécies domésticas, e de 167 a 513 UI/L, para caprinos adultos $^{21}$. No presente trabalho, a atividade sérica de AST variou entre $24,22 \pm 4,86 \mathrm{UI} / \mathrm{L}$ ao nascimento e $106,06 \pm 60,76 \mathrm{UI} / \mathrm{L}$ aos 75 dias de vida.

Segundo Silva, Fagliari e Cesco ${ }^{32}$, a atividade sérica da AST, em caprinos da raça Saanen criados no estado de São Paulo, foi de 76,68 $\pm 22,06$ U/L (machos) e de $85,44 \pm 15,94 \mathrm{U} / \mathrm{L}$ (fêmeas), para animais com até 90 dias de idade. Estes valores são superiores aos encontrados no presente estudo, desde o nascimento até 30 dias de idade, e inferiores à atividade observada aos 75 dias (Tabela 2). Mantiveram-se, no entanto, dentro do intervalo de referência apresentado por Pérez et al. ${ }^{22}$, de 26,6 a 1758,0 UI/L.

Apesar de se observarem diferenças significativas na atividade da AST entre os momentos (Tabela 2), estas não apresentaram indícios de aumento ou decréscimo em seus valores com relação à idade, não permitindo inferir que o fator etário exerceu influência sobre es-

Tabela 2 - Médias e desvios-padrão das atividades séricas de aspartatoaminotransferase (AST), fosfatase alcalina (FA), gamaglutamiltransferase (GGT), e concentrações séricas de creatinina e ureia, e da glicose de cabritos da raça Bôer $(n=25)$ desde o nascimento até 75 dias de vida - Araçatuba - 2010

\begin{tabular}{|c|c|c|c|c|c|c|}
\hline \multirow{2}{*}{ Variável } & \multicolumn{6}{|c|}{ Momento (dias) } \\
\hline & $\mathbf{0}$ & 2 & 7 & 15 & 30 & 75 \\
\hline $\begin{array}{c}\text { AST } \\
(\mathrm{UI} / \mathrm{L})\end{array}$ & $\begin{array}{l}24,22^{c} \\
(4,86)\end{array}$ & $\begin{array}{c}57,43^{\mathrm{bc}} \\
(9,29)\end{array}$ & $\begin{array}{c}62,67^{\mathrm{ab}} \\
(4,92)\end{array}$ & $\begin{array}{c}53,39^{\mathrm{bc}} \\
(5,23)\end{array}$ & $\begin{array}{c}57,83^{\text {abc }} \\
(8,53)\end{array}$ & $\begin{array}{l}106,06^{\mathrm{a}} \\
(60,76)\end{array}$ \\
\hline$\underset{(\mathrm{UI} / \mathrm{L})}{\mathrm{FA}}$ & $\begin{array}{c}240,30^{\text {abcd }} \\
(93,41)\end{array}$ & $\begin{array}{l}440,40^{\mathrm{abc}} \\
(180,58)\end{array}$ & $\begin{array}{c}483,69^{\mathrm{a}} \\
(114,91)\end{array}$ & $\begin{array}{l}450,94^{\mathrm{ab}} \\
(211,48)\end{array}$ & $\begin{array}{c}292,57^{\text {abcd }} \\
(194,81)\end{array}$ & $\begin{array}{l}91,99^{\mathrm{d}} \\
(24,34)\end{array}$ \\
\hline $\begin{array}{c}\text { GGT } \\
(\mathrm{UI} / \mathrm{L})\end{array}$ & $\begin{array}{l}39,70^{\mathrm{e}} \\
(8,18)\end{array}$ & $\begin{array}{l}187,16^{a} \\
(62,46)\end{array}$ & $\begin{array}{c}75,71^{\mathrm{b}} \\
(18,40)\end{array}$ & $\begin{array}{l}52,85^{\mathrm{cd}} \\
(9,35)\end{array}$ & $\begin{array}{l}46,83^{\mathrm{de}} \\
(7,45)\end{array}$ & $\begin{array}{l}64,75^{b c} \\
(17,12)\end{array}$ \\
\hline $\begin{array}{l}\text { Creatinina } \\
(\mathrm{mg} / \mathrm{dL})\end{array}$ & $\begin{array}{l}2,52^{\mathrm{a}} \\
(0,35)\end{array}$ & $\begin{array}{l}2,29^{a b} \\
(0,74)\end{array}$ & $\begin{array}{l}1,59^{c} \\
(0,37)\end{array}$ & $\begin{array}{c}1,40^{\mathrm{c}} \\
(0,16)\end{array}$ & $\begin{array}{l}1,55^{\mathrm{c}} \\
(0,16)\end{array}$ & $\begin{array}{l}1,38^{\mathrm{c}} \\
(0,16)\end{array}$ \\
\hline$\underset{(\mathrm{mmol} / \mathrm{L})}{\text { Ureia }}$ & $\begin{array}{l}6,75^{\mathrm{a}} \\
(0,91)\end{array}$ & $\begin{array}{c}6,75^{\mathrm{a}} \\
(1,74)\end{array}$ & $\begin{array}{l}3,34^{\mathrm{c}} \\
(0,92)\end{array}$ & $\begin{array}{c}3,45^{c} \\
(0,90)\end{array}$ & $\begin{array}{l}5,28^{\mathrm{ab}} \\
(1,58)\end{array}$ & $\begin{array}{l}6,64^{\mathrm{a}} \\
(1,25)\end{array}$ \\
\hline $\begin{array}{l}\text { Glicose } \\
(\mathrm{mg} / \mathrm{dL})\end{array}$ & $\begin{array}{c}41,22^{\mathrm{c}} \\
(17,59)\end{array}$ & $\begin{array}{l}115,44^{\mathrm{a}} \\
(23,67)\end{array}$ & $\begin{array}{l}112,08^{a} \\
(18,54)\end{array}$ & $\begin{array}{l}106,16^{\mathrm{ab}} \\
(17,06)\end{array}$ & $\begin{array}{c}75,60^{\mathrm{c}} \\
(13,96)\end{array}$ & $\begin{array}{l}44,68^{\mathrm{c}} \\
(9,78)\end{array}$ \\
\hline
\end{tabular}

Médias seguidas de letras distintas, na linha, diferem entre si $(\mathrm{p}<0,05)$ 
tas. Há divergências na literatura quanto às variações de AST, em função da faixa etária. Rêgo ${ }^{33}$ não verificou tais diferenças, ao contrário de Behera et al. ${ }^{34}$, que encontraram variação significativa em relação à idade dos animais, e Silva, Fagliari e $\mathrm{Cesco}^{32}$, que além da faixa etária, observaram diferenças relacionadas à raça e sexo.

Entre o nascimento e dois dias de idade não se verificou diferença significativa da atividade da AST (Tabela 2), sugerindo que seus valores não foram influenciados pela ingestão de colostro, concordando com os resultados obtidos por Britti et al. ${ }^{35} \mathrm{em}$ ovinos, que relataram que a elevação da referida enzima não estava associada à ingestão de colostro. Mesmo observando aumento significativo nos valores de AST entre os momentos antes da ingestão de colostro $(27,8 \pm 11,8$ $\mathrm{UI} / \mathrm{L})$, e após 24 horas (128 $\pm 37 \mathrm{UI} / \mathrm{L})$, com posterior declínio aos dois dias de vida $(95,6 \pm 55,3 \mathrm{UI} / \mathrm{L})$, estes autores não encontraram correlação entre a atividade da AST e a concentração de IgG, sugerindo que o aumento observado foi consequência da produção endógena, como verificado, por exemplo, em lesões musculares decorrentes do parto.

A atividade sérica da FA não apresentou variação significativa nos primeiros 30 dias de vida (Tabela 2), com o menor valor médio observado aos 75 dias pósnascimento, que diferiu significativamente das determinações realizadas aos dois, sete e 15 dias (Tabela 2). Nestes últimos, os valores foram pouco superiores ao intervalo de referência para a espécie, de 93 a 387 $\mathrm{UI} / \mathrm{L}^{21}$; porém, os valores séricos de FA em caprinos podem aumentar até dez vezes sem evidência de dano hepático ${ }^{36}$, e a elevação da FA pode ocorrer durante os períodos que ocorrem maior atividade óssea, como a fase de crescimento rápido ${ }^{37}$, período em que se encontravam os animais do presente estudo.

Como observado anteriormente para a atividade sérica da AST, a FA não apresentou aumento significativo após a ingestão de colostro (Tabela 2). Este resultado é, em parte, confirmado pelos achados de
Britti ${ }^{35} \mathrm{em}$ ovinos, que, apesar de observarem aumento significativo desta enzima após 24 horas da ingestão de colostro, este não foi devido à presença de FA no colostro, e sim por a mesma encontrar-se presente nas bordas das vilosidades intestinais, e ser carreada para a circulação, juntamente com as proteínas absorvidas pelo epitélio intestinal ${ }^{38}$.

A atividade sérica da GGT apresentou aumento significativo aos dois dias de vida (Tabela 2), em decorrência da absorção desta enzima pela mucosa intestinal, como previamente descrito em bovinos por Braun et al. ${ }^{14} \mathrm{e}$ em caprinos por Silva et al. ${ }^{12}$, pois o colostro possui grande quantidade de GGT, como já demonstrado em bovinos ${ }^{3}$ e ovinos $^{35,39}$.

Segundo Braun et al. ${ }^{14}$, a atividade de GGT foi baixa ( $\leq 28 \mathrm{UI} / \mathrm{L}$ ) em bovinos recém-nascidos antes de mamar, sendo de 127 UI/L, às 24 horas após o nascimento, com posterior decréscimo nos dias subsequentes, dinâmica semelhante à observada por Silva et al. ${ }^{12} \mathrm{em}$ cabritos que mamaram colostro caprino de primeira e segunda ordenha, com atividade sérica da GGT de $56,6 \pm 12,6 \mathrm{UI} / \mathrm{L}$, antes da ingestão de colostro, e de $126,6 \pm 67,1 \mathrm{UI} / \mathrm{L}$, às 48 horas de vida, acompanhada de valores decrescentes até 72 horas pós-nascimento. No presente estudo, observou-se variação semelhante à relatada por estes autores, com declínio significativo aos sete dias de idade (Tabela 2). A partir dos 15 dias pós-nascimento, os valores aproximaram-se da atividade normal relatada na literatura, de 20 a $56 \mathrm{UI} / \mathrm{L}^{21} \mathrm{e}$ de $51,0 \pm 25,3 \mathrm{UI} / \mathrm{L}^{22}$.

A concentração sérica de creatinina foi significativamente maior logo após o nascimento e aos dois dias de idade, quando comparada àquela dos demais momentos avaliados (Tabela 2). Segundo Finco ${ }^{40}$, a função renal do neonato, ao nascimento, possui menor capacidade de concentrar a urina devido à imaturidade renal, porém são poucos os estudos referentes à função renal em recém-nascidos.

Até os dois dias de vida, os animais apresentaram valores de creatinina superiores ao intervalo de referên- 
cia, de 1,0 a $1,8 \mathrm{mg} / \mathrm{dL}^{21}$, sendo que, a partir dos sete dias pós-nascimento, estes valores já se encontravam dentro do intervalo de referência (Tabela 2). Associadas à imaturidade da função renal, estas maiores concentrações de creatinina refletem, possivelmente, o maior metabolismo da creatina logo após o parto, pois há a necessidade de maior fonte energética para a atividade muscular, que pode ser obtida pela reação catabólica da creatina, com decomposição em creatinina ${ }^{40}$, que não foi adequadamente excretada na urina.

Observaram-se diferenças significativas na concentração de ureia dos cabritos entre os momentos avaliados (Tabela 2). Entretanto, todos os valores estiveram próximos do intervalo de referência para a espécie, de 3,57 a 7,14 mmol/L $\mathrm{L}^{21}$, e 7,39 $\pm 2,58 \mathrm{mmol} /$ $\mathrm{L}^{22}$.Os maiores valores de ureia observados até os dois dias de vida (Tabela 2) podem ser consequência do mesmo fator que influenciou a concentração de creatinina, qual seja, a menor capacidade excretora renal. Com a maturação da função renal, observou-se diminuição das concentrações de ureia aos sete e 15 dias de vida (Tabela 2). Os teores foram mais elevados aos 30 e 75 dias, provavelmente, devido ao aumento da produção de ureia, por elevação no metabolismo proteico ${ }^{40}$, visto que, neste período, os animais já eram suplementados com fontes concentradas de proteína, além daquelas oriundas da amamentação.

Observou-se variação significativa da concentração de glicose entre os momentos (Tabela 2), com menores taxas logo após o nascimento, seguida de significativo aumento, aos dois dias. Os níveis de glicose

\section{Referências}

1. PATEL, M. S.; VAN LELYVELD, P.; HANSEN, R. W. The development of the pathways of glucose homeostasis in the newborn. In: JONES, C. T. (Ed.) The biochemical development of the fetus and neonate. Amsterdam: Elsevier Biomedical Press, 1982.

2. YOUNG, J. W.; OTCHERE, E. O.; TRENKLE, A.; JACOBSON, N. L. Effect of age on glucose, reducing sugars and plasma insulin in blood of milk fed calves. Journal of Nutrition, v. 100, n. 11, p. 1287, 1970.

3. DANIELS, L. B.; PERKINS, J. L.; KRIEDER, D.; TUGWELL, são influenciados pelo momento de coleta, sendo os menores valores observados ao nascimento, seguidos, logo após a ingestão do colostro, da elevação gradual e significante, até as 48 horas, permanecendo, por fim, estáveis até as 96 horas, em estudos realizados com bovinos ${ }^{5,41}$ e em caprinos ${ }^{42}$. Portanto, o aumento da glicemia no presente trabalho deveu-se à ingestão de colostro, que além da importante função na transferência de imunidade passiva, citada anteriormente, também possui marcantes características nutricionais, demonstradas por Argüello ${ }^{25}$.

Até os 15 dias de vida, observou-se estabilização da concentração de glicose dos cabritos, mantida, neste período, pela ingestão de leite. Segundo Kuhne et al. ${ }^{5}$, a concentração plasmática de glicose dos ruminantes neonatos depende diretamente da quantidade ingerida e da concentração de lactose presente na secreção láctea. A partir dos 30 dias de idade, os cabritos tiveram declínio significativo dos níveis de glicose, devido, possivelmente, à diminuição da produção de leite pelas cabras; aos 75 dias, os níveis estavam próximos aos relatados para animais adultos, de 50 a $75 \mathrm{mg} /$ $\mathrm{dL}^{21}$, e de $126,1 \pm 66,0 \mathrm{mg} / \mathrm{dL}^{22}$.

\section{Conclusões}

Conclui-se que os perfis do proteinograma, glicemia e dos demais componentes bioquímicos séricos estudados em cabritos, desde o parto até 75 dias de vida, variaram em decorrência de causas fisiológicas e/ou influenciadas pelo manejo nutricional dos animais.

D.; CARPENTER, D.Blood glucose and fructose in the newborn ruminant. Journal of Dairy Science, v. 57, n. 10, p. 1196,1974

4. STANKO, R. L.; GUTHRIE, M. J.; RANDEL, R. D. Response to environmental temperatures in Brahman calves during the first compared to the second day after birth. Journal of Animal Science, v. 69, n. 11, p. 4419-4427, 1991.

5. KUHNE, S.; HAMMON, H. M.; BRUCKMAIER, R. M.; MOREL,C.; ZBINDEN, Y.; BLUM, J. W. Growth performance, metabolic and endocrine traits, and intestinal absorptive 
capacity in neonatal calves fed either colostrum or milk replacer at low and high intensities.Journal of Animal Science, v. 78, n. 3 , p. 609-620, 2000.

6.ZARRILLI, A.; MICERA, E.; LACARPIA, N.; LOMBARDI, P.; PERO, M. E.; D'ANGELO, D.; MATTIA, M.; AVALLONE, L. Evaluation of goat colostrum quality by determining enzyme activity levels.Livestock Production Science, v. 83, n. 2, p. 317-320, 2003.

7.KANEKO, J. J. Serum proteins and the dysproteinemias. In: KANEKO, J. J. (Ed.). Clinical biochemistry of domestic animals. 4. ed. San Diego: Academic Press, 1989. p. 142-165.

8. MELLADO, M.; DEL ANGEL, E.; REBOLLOSO, O.; GARCÍA, E. Immunoglobulin $\mathrm{G}$ concentration and neonatal survival of goat kids delivered in a pen or on open range. Preventive Veterinary Medicine, v. 37, n. 1/4, p. 33-39, 1998.

9. O'BRIEN, J. P.; SHERMAN, D. M. Serum immunoglobulin concentrations of newborn goat kids and subsequent kid survival through weaning. Small Ruminant Research, v. 11, n. 1, p. 71-77, 1993.

10.CHEN, J. C.; CHEN, J. C.; CHANG, C. J.; PEH, H. C.; CHEN, $S$. Y.Serum protein levels and neonatal growth rate of Nubian goat kids in Taiwan area. Small Ruminant Research, v. 32, n. 2, p. 153-160, 1999.

11.SANTOS, T. G.; BERTOLINI, D. A.; MACEDO, F. A F.; PRADO, I.N.; MARTINS, E.N. Variabilidade em imunoglobulina $G$ ( $\operatorname{IgG}$ ) no colostro de cabra de primeira ordenha e absorção intestinal de IgG pelos cabritos recémnascidos. Brazilian Archives of Biology and Technology, v. 37, p. 285-292, 1994

12.SILVA, S. L.; FAGLIARI, J. J.; BAROZA, P. F. J.; CESCO, F. T.R. S.; JORGE, R. L. N. Avaliação da imunidade passiva em caprinos recém-nascidos alimentados com colostro de cabras ou colostro de vacas. Ars Veterinária, v. 23, n. 2, p. 81-88, 2007.

13. SIMÕES, S. V. D.; COSTA, R. .G.; SOUZA, P. M.; MEDEIROS, A. N.; VILAR, A. L. T. Imunidade passiva, morbidade neonatal e desempenho de cabritos em diferentes manejos de colostro. Pesquisa Veterinária Brasileira, v. 25, n. 4, p. 219-224, 2005.

14.BRAUN, J. P.; TAINTURIER, D.; LAUGIER, C.; BÉNARD, P.; THOUVENOT, J. P.; RICO, A. G. Early variations of blood plasma gamma glutamyltransferase in newborn calves - a test of colostrum intake. Journal of Dairy Science, v. 65, n. 11, p. 2178-2181, 1982

15.FEITOSA, F. L. F. (Ed.). Semiologia veterinária: a arte de diagnóstico. 2. ed. São Paulo: Roca, 2008. 735 p.

16. FRIEDMAN, H. S. A standardized procedure for serum protein electrophoresis on cellulose acetate membrane strips. ClinicaChimicaActa, v. 6, p. 775-781, 1961.

17.KREMERS, B.; BRIERE, R. O.; BATASAKIS, J. G. Reflectance densitometry of cellulose acetate protein electrophoresis. American Journalof Medical Technology, v. 33, n. 1, p. 2834, 1967.

18.STRUFALDI, B. Prática de bioquímica clínica. São Paulo: Faculdade de Ciências Farmacêuticas, USP, 1987. 339 p.

19.FAHEY, J. L.; McKELVEY, E. M. Quantitative determination of serum immunoglobulins in antibody agar plates. Journal of Immunology, v. 94, n. 1, p. 84, 1965.

20.MANCINI, G.; CARBONARA, A. O.; HEREMANS, J. F. Immunochemical quantitation of antigens by single radial immunodiffusion. Immunochemistry, v. 2, n. 3, p. 235-254, 1965.

21.KANEKO, J. J. (Ed.). Clinical biochemistry of domestic animals. 4. ed. San Diego: Academic Press, 1989. 932 p.
22.PÉREZ, J. M.; GONZÁLEZ, F. J.; GRANADOS, J. E.; PÉREZ, M. C.; FANDOS, P.; SORIGUER, R. C.; SERRANO, E. Hematologic and biochemical reference intervals for spanish Ibex. Journal of Wildlife Diseases, v. 39, n. 1,p. 209-215, 2003.

23.LEVIEUX, D.; MORGAN, F.; GENEIX, N.; MASLE, I.; BOUVIER, F.Caprine immunoglobulin G, $\beta$-lactoglobulin, $\alpha$-lactalbumin and serum albumin in colostrum and milk during the early post partum period. Journal of Dairy Research, v. 69, n. 3, p. 391-399, 2002.

24. McDOUGALL, E. I. Proteins of ruminant colostrum. The Biochemical Journal, v. 94, n. 1, p. 99-100, 1965.

25.ARGÜEllo, A.; CASTRO, N.; ÁlVAREZ, S.; CAPOTE, J. Effects of the number of lactations and litter size on chemical composition and physical characteristics of goat colostrum. Small Ruminant Research, v. 64, n. 1/2, p. 53-59, 2006.

26.RUDOVSKY, A.; LOCHER, A.; ZEYNER, A.; SOBIRAJ, A.; WITTEK, T. Measurement of immunoglobulin concentration in goat colostrum. Small Ruminant Research, v. 74, n. 1/3, p. 265-269, 2008.

27. ARGÜEllO, A.; CASTRO, N.; ZAMORANO, M. J.; CASTROALONSO, A.; CAPOTE, J. Passive transfer of immunity in kid goats fed refrigerated and frozen goat colostrum and commercial sheep colostrum. Small Ruminant Research, v. 54, n. 3, p. 237-241, 2004.

28.CONSTANT, S. B.; LeBLANC, M. M.; KLAPSTEIN, E. F.; BEEBE, D. E.; LENEAU, H. N.; NUNIER, C. J. Serum immunoglobulin $\mathrm{G}$ concentration in goat kids fed colostrum or a colostrums Substitute. Journal of American Veterinary Medical Association, v. 205, n. 12, p. 1759-1762, 1994.

29.SANTANA, A. F.; SILVA, M. H.; ANUNCIAÇÃO, A. V. M.; GUARDIANI, B. P.; RIBEIRO, A. C.; BRAZIL, B. N.; AGUIAR, C. S. Transferência de imunidade passiva em cabritos. In: CONGRESSO PERNAMBUCANO DE MEDICINA VETERINÁRIA, 5.; SEMINÁRIO NORDESTINO DE CAPRINO-OVINOCULTURA, 6., 2003, Recife, Brasil. Anais... 2003. p. 389-390.

30.BIRGEL, E. H. Variações dos teores proteicos do sangue de caprinos durante o desenvolvimento etário. Revista da Faculdade de Medicina Veterinária da Universidade de São Paulo, v. 8, n. 1, p. 299-315, 1969.

31. KERR, M. G. Exames laboratoriais em medicina veterinária. São Paulo: Roca, 2003. 436 p.

32.SILVA, S. L.; FAGLIARI, J. J.; CESCO, F. T. R. S. Atividade sérica das enzimas AST, ALP e GGT de caprinos das raças Anglo-nubiana e Saanen criados nos estados de São Paulo e Paraíba. Ars Veterinária, v. 20, n. 1, p. 22-27, 2004.

33. RÊGO, E. W. Contribuição ao estudo da bioquímica clínica de caprinos (Capra hircus) criados no estado de Pernambuco: influência de fatores de variabilidade etário e sexual.2000. 64 p. Tese (Doutorado em Clínica Veterinária) Faculdade de Medicina Veterinária e Zootecnia, Universidade de São Paulo, São Paulo,2000.

34.BEHERA, P. C.; BISOI, P. C.; MOHAPATRA, M.; RAO, P. K.Serum enzyme activity in different age groups of male and female Black Bengal goats. Indian Veterinary Journal, v. 70, n. 11, p. 1042-1045, 1993.

35.BRITTI, D.; MASSIMINI, G.; PELI, A.; LUCIANI, A.; BOARI, A. Evaluation of serum enzyme activities as predictors of passive transfer status in lambs. Journal of American Veterinary Medical Association, v. 226, n. 6, p. 951-955, 2005.

36. KRAMER, J. W. Clinical enzymology. In: KANEKO, J. J. (Ed.). Clinical biochemistry of domestic animals. 4. ed. San Diego: Academic Press, 1989. p. 338-363. 
37.MEYER, D. J.; COLES, E. H.; RICH, L. J. Medicina de laboratório veterinária: interpretação e diagnóstico. São Paulo: Roca, 1995. 308 p.

38.TENNANT, B. C.; HORNBUCKLE, W. E. Gastrointestinal function. In: KANEKO, J. J. (Ed.). Clinical biochemistry of domestic animals. 4. ed. San Diego: Academic Press, 1989, p. 417-461.

39.MADEN, M.; ALTUNOK, V.; BIRDANE, F. M.; ASLAN, V.; NIZAMLIOGLU, M. Blood and colostrum/milk serum $\gamma$-glutamyltransferase activity as a predictor of passive transfer status in lambs. Journal of Veterinary Medicine B, infectious diseases and veterinary public health, v. 50, n. 3, p. $128-131,2003$.
40.FINCO, D. R. Kidney function. In: KANEKO, J. J. (Ed.). Clinical biochemistry of domestic animals. 4. ed. San Diego: Academic Press, 1989. p. 496-542.

41.PAIVA, F. A.; NEGRÃO, J. A.; BUENO, A. R.; SARAN-NETTO, A.; LIMA, C. G. Efeito do manejo de fornecimento de colostro na imunidade passiva, cortisol e metabólitos plasmáticos de bezerros Holandeses. Arquivo Brasileiro de Medicina Veterinária e Zootecnia, v. 58, n. 5, p. 739-743, 2006.

42. CAMARGO, D. G. Avaliação do sistema APGAR (modificado por BORN, 1981) e dos níveis de cortisolemia, glicemia e de gases sanguíneos em cabritos nascidos de partos eutócicos e de cesariana. 2010. 102 p. Dissertação (Mestrado em Ciência Animal) - Faculdade de Medicina Veterinária de Araçatuba, Universidade Estadual Paulista, Araçatuba, 2010. 